\title{
Revista

\section{DE LA IDENTIDAD FOLCLÓRICA A LA REIVINDICACIÓN DEL BUEN VIVIR}

Laura Collin Harguindeguy

El Colegio de Tlaxcala A. C. lauracollin@gmail.com

\section{RESUMEN}

Si bien, prácticamente desde los albores de la disciplina, el relativismo cultural prescribía el respeto a las culturas otras, al menos desde hace cuatro décadas, con posterioridad a la reunión de Barbados, buena parte de los antropólogos hemos asumido, como parte de nuestra labor, la revalorización de las culturas étnicas. Esta tarea ha sido abordada tanto desde la academia como desde la antropología aplicada, con proyectos para el rescate del patrimonio cultural. Es más, en parte por nuestra labor, los propios pueblos indios tienden a identificar patrimonio cultural, cultura e identidad. En el artículo se argumenta en torno a la necesidad de superar esta visión folclórica de la cultura y la identidad, para transitar a la revaloración de las lógicas implícitas, como parece hacerlo la propuesta del buen vivir.

PALABRAS CLAVE: culturas étnicas, racionalidades alternas, buen vivir, patrimonio cultural.

\section{FOLKLORIC IDENTITY AND RECLAIMING GOOD LIVING}

\section{ABSTRACT}

Cultural relativism has prescribed respect for other cultures practically since its beginning. In spite of this, at least since the last four decades, following the Barbados Meeting, a large number of anthropologists have taken on the revaluing of ethnic cultures as part of our work. Both academia and applied anthropology have approached this task with projects aiming to retrieve cultural heritage. Furthermore, it is in part due to our work as anthropologists that indigenous peoples have tended to identify cultural heritage, culture and identity. This article addresses the need to overcome a folkloric vision of culture and identity and thus move toward revaluing the implicit logic, as supported by the buen vivir 'good living' proposal.

KEYWORDS: Ethnic cultures, alternate rationalities, buen vivir, cultural heritage. 


\section{DE LAS DECLARACIONES DE BARBADOS \\ AL ETNICISMO FOLK}

as declaraciones de Barbados (1971 y 1974), en sus dos versiones, inauguran el cambio de perspectiva de la antropología integracionista a la liberacionista, donde los involucrados en esta práctica pasarían de redentores a asesores de los incipientes movimientos indígenas, y en no pocas ocasiones en sus demiurgos. El cambio de perspectiva en la profesión provocó una profunda crisis y la ruptura de lo que había sido un triángulo operativo: investigación, formación de nuevos cuadros y la disciplina aplicada en México, representado en tres instituciones: el Instituto Nacional de Antropología e Historia (INAH), la Escuela Nacional de Antropología e Historia (ENAH) y el entonces Instituto Nacional Indigenista (INI).

La idea original de distinción entre los niveles analítico y aplicado de la disciplina se debió a Moisés Sáenz, el precursor olvidado —como lo denominó Javier Guerrero (1975)—, quien diseñó el programa indigenista estatal. El maridaje de la antropología con el Estado fue tal, que la carrera no se incluyó en la oferta curricular de la muy autónoma Universidad Nacional, sino que, al igual que el Instituto Politécnico Nacional y Chapingo, dependería de la Secretaría de Educación Pública. Cada una de estas instituciones se encargaría de formar intelectuales orgánicos para tareas consideradas centrales por el régimen revolucionario para el desarrollo industrial, el agrícola y la integración nacional. Cuando los antropólogos tomaron conciencia de su participación como agentes en esta forma de colonialismo interno, sobrevino el divorcio, con renuncias de profesores, creación de otras carreras, renuencia de los egresados a ingresar en perversas instituciones como el INI. Sin embargo, algunos de los destacados participantes de las reuniones de Barbados siguieron vinculados al gobierno, que con esa capacidad incluyente demostrada desde la revolución triunfante asumió parte del discurso liberacionista y ofreció a los rebeldes la posibilidad de hacer más cosas trabajando desde dentro del sistema.

Una de esas acciones, se rumora, fue la promoción institucional de la organización indígena, orquestada desde el INI y la Confederación Nacional Campesina, liderada en ese momento por el hermano de uno de los antropólogos críticos participante y difusor de las tesis de Barbados en México. Así, mutatis mutandis, el indigenismo transmutó de integracionista a indigenismo de participación (Báez-Jorge 1979), para luego adoptar las tesis del etnodesarrollo (Bonfil 1995). Una vez incorporadas las tesis contestatarias al lenguaje institucional, comenza- 
ron a aparecer las propuestas de los ahora intelectuales orgánicos al servicio del movimiento indígena, orientadas a dotar a sus líderes de los instrumentos para la lucha de liberación. Se crearía así la licenciatura en etnolingüística (CIESAS, INI, $S E P$ ), el programa de técnicos bilingües en cultura indígena (DGCP, INI, SEP), el programa de defensa del patrimonio cultural (INI), entre otros. Algunos egresaron de la carrera técnica y luego de cursar la licenciatura siguieron posgrados, y se convirtieron en intelectuales indígenas (Collin 2003), mientras jóvenes de los pueblos indios entraban en la ENAH en busca de su identidad perdida.

Así planteado, el proyecto parecía coherente, solo que en la práctica los contenidos heurísticos, por lo general, se limitaron al rescate folclórico de los rasgos diacríticos. ¿Que hicieron los programas mencionados? Festivales de música indígena, ediciones de discos, muestras artesanales, recopilaciones de leyendas y cuentos, con sus respectivas ediciones, al punto que en la actualidad los egresados de los programas siguen pensando que su cultura son sus leyendas, su música, su artesanía, una imagen inmovilista y estereotipada de ser indio. La prioridad de los aspectos folclóricos de la cultura sobre los demás componentes fue tal que, puestos a pensar en el modelo maya de desarrollo, doctorantes indígenas insistían en recopilar el sistema festivo y ritual.

El segundo resultado tuvo que ver con la revaluación de la identidad devaluada. El complejo de inferioridad lo habría definido tempranamente Julio de la Fuente (1977), y a partir del posicionamiento de la corriente liberacionista se coincidió en la necesidad de dicha revaluación, solo que en el proceso de la reivindicación de los pueblos indios también se abonó a una nueva leyenda negra sobre el proceso colonial, que en vez de analizar comparativamente las culturas, llevó a una mistificación acrítica del pasado prehispánico.

Desde el punto de vista práctico, el principal resultado ha sido la legitimación de los usos y costumbres, en ocasiones de manera irreflexiva, incluidos el machismo y el caciquismo.

\section{ACERCA DEL CONCEPTO DE CULTURA}

¿A qué se debe la folclorización de los componentes de la cultura y de la identidad? En parte se explica por el concepto empleado; en otra, por la limitada utilización de los términos para el análisis concreto. Casi todos los antropólogos revisamos y estudiamos varias versiones de la palabra cultura, desde las abarcativas, según las cuales todo está incluido en esa palabra, a las descriptivas, 
que separan tipos de componentes: artefactos, mente-factos, ideo-factos. Por mi parte adopto la formulada en 1971 por Goodenough y luego retomada por Geertz (1987), que a mi juicio resulta operativa: ver, juzgar y actuar, es decir, una forma de establecer las relaciones y las valoraciones entre las cosas, esto es, un sistema lógico. La cultura no radicaría así en las cosas, dice Goodenough, sino en la manera de hacerlas; no es la música, no es la ropa, sino cómo se relacionan, cómo se valoran; no es la semántica, sino la gramática. La cultura material suele cambiar rápidamente. Las estructuras de pensamiento y razonamiento no tanto.

Propongo, entonces, buscar las raíces de la cultura que permiten construir sistemas de identidad en los aspectos de pensamiento que implican una lógica, no necesariamente en los detalles sobre dioses o la forma de celebrarlos. Ver significa qué cosas, qué entes se reconocen y, por tanto, se nombran; juzgar: el valor que se les concede; bueno, malo, útil, nocivo, y así, mientras que actuar supone la forma de tratarlas, es decir, el sistema de relaciones, con las cosas y entre las personas.

En su momento, los antropólogos de Barbados tenían razón al plantear la posibilidad de un modelo civilizatorio alterno, pero tal cosa no puede limitarse a fiestas y rituales, ni proponerse a quienes no son indios que se indianicen y que adopten su vestido, música o tradiciones. Si se pretende acceder o proponer un modelo civilizatorio, se requiere explorarlo o definirlo, es decir, la abstracción de las características esenciales, para que opere y se reproduzca un sistema. Al respecto cabe recordar la distinción de Marx (1971) entre modo de producción — que en este caso sería modelo- y formación económica y social (FES), como expresión de la realidad compleja, donde pueden aparecer diferentes lógicas. Identificar un modelo supone un proceso de abstracción. Mencionar la existencia de modelos, como abstracción lógica, no supone negar la diversidad, sino que a partir del análisis de muchos casos se pueden abstraer elementos comunes como para definir un modelo. Si bien como antropólogos somos defensores de la diversidad, como analistas, pero sobre todo como antropólogos comprometidos, resulta importante poder identificar modelos. Precisamente si una de las aportaciones de la antropología es haber evidenciado la alteridad, otra no menos importante es demostrar que las posibilidades combinatorias resultan limitadas.

Con frecuencia, en el campo mexicano de la antropología se confunde lengua, cultura y sistema político. Se menciona al grupo étnico náhuatl como si se pudiera homologar a los hablantes de náhuatl (con o sin tl) de Nayarit con los de Veracruz, con 700 años de separación y, por tanto, con experiencias diferen- 
tes, pero también se incluye como náhuatl al imperio mexica, tanto como a los tlaxcaltecas, como si fueran una entidad y por eso se considera a los de Tlaxcala traidores, cuando se trataba de configuraciones políticas diferentes, $y$, en ese caso concreto, enemigas. En sentido contrario, con respecto a la particularidad, cuando se habla de cultura, una configuración cultural puede constituir un horizonte y ser común a pueblos de estructura política y lengua diferentes; es el caso de la globalización, donde a escala mundial se comparten ciertos patrones; lo fue respecto del área cultural que Kirchhoff (1975) definió como Mesoamérica, caracterizada por compartir patrones culturales.

Con base en el análisis de esos patrones se puede abstraer un modelo, que sería diferente de las conformaciones políticas de su momento y del actual, pues han transcurrido 500 años desde la Conquista y las culturas son dinámicas. Abstraer un modelo cultural, más allá de los hechos concretos, es factible, pero al hacerlo es preciso analizar las relaciones lógicas en términos de sistema, como se ha hecho reiteradamente para nuestra sociedad, sin abandonar la perspectiva crítica.

Después de 40 años de los encuentros de Barbados, la posibilidad de una opción civilizatoria comienza a tener nombre: el buen vivir, y carta de identidad al figurar en dos constituciones latinoamericanas; de manera creciente comienza a aparecer como tema de investigación en foros académicos, lo cual resulta sin duda saludable. Sin embargo, aún persiste la tendencia particularista, así como la que confunde el agrupamiento político con la lengua y la cultura.

\section{LA REIFICACIÓN DEL PASADO INDÍGENA}

Característico de esas confusiones es el texto que en el Diccionario de economía (Cattani, Coraggio y Laville 2009) define la economía comunitaria. Chiroque y Muteberria (2009) la identifican con la practicada por los pueblos originarios y campesinos. En una mélange apologética que salta de las prácticas prehispánicas de sociedades estatales altamente centralizadas, como los incas o los mayas, a las realidades comunitarias actuales, encuentran valores como el respeto a la naturaleza (de dudosa aplicación entre los mayas) y distribución igualitaria del excedente no aplicable a ninguna de las sociedades estatales con nobleza y clase sacerdotal ${ }^{1}$ y la prioridad del valor de uso. En la búsqueda de las prácticas diferen-

${ }^{1}$ El texto de referencia comparte la confusión, frecuente en los etnicistas, entre cultura, lengua y organización política. A las sociedades campesinas, o los productores y comunidades campesinas, base social de los estados maya o inca, preexistentes y sobrevivientes de la organización del Estado 
ciales rescatan experiencias sociales vigentes como la reciprocidad simétrica en la construcción de la vivienda, que datan en el área aymará y existente en México en cada vez menos lugares, así como el concepto quechua de buen vivir: sumak kawsay y el vivir bien: suma qamaña, así como la presencia viva de la solidaridad y la reciprocidad. Los autores presuponen que las culturas arcaicas poseen valores de respeto por los seres humanos y por la naturaleza, afirmación que puede ser cuestionada en el caso de las sociedades estatales que recurrieron al trabajo esclavo, tenían una rígida estratificación y, al menos en el caso de los mayas, se cuestiona su respeto por la naturaleza. De cualquier modo, se requieren estudios a profundidad de los modelos de desarrollo o de adaptación a las condiciones ambientales para establecer cuál es el grado de sustentabilidad de las culturas aborígenes. Los autores, que pueden ser catalogados como etnicistas, ${ }^{2}$ suponen la existencia de medios de producción colectivos, que no se constatan en la información etnográfica, o al menos habría que preguntarse cuáles medios de producción pueden ser considerados colectivos y cuáles se apropian de manera privada. El aspecto que ha sido objeto de múltiples indagaciones etnográficas es el tocante a la existencia de derechos y obligaciones culturalmente establecidos. En México, al menos implica formas de trabajo obligatorio, que suponen formas no monetarias de tasas, en tanto todos los adultos deben participar en faenas que involucran trabajos comunitarios. ${ }^{3}$ La exigencia del trabajo comunitario ha sido considerada desde la perspectiva liberal como ilegal, en tanto supone un atentado a la libertad de trabajo; sin embargo, los límites entre trabajo obligatorio e impuestos suelen ser sutiles; la demanda del impuesto en dinero compele la búsqueda de trabajo asalariado para pagar la tasa, que constituye otra forma de compulsión u obligatoriedad, mientras que el pago con trabajo aparece en este caso como menos compulsivo, pues el miembro de la comunidad presta el servicio en tiempo y no en dinero.

centralizado, probablemente se les puedan atribuir las lógicas y prácticas mencionadas, no así a los mayas o incas, término que denota un Estado estratificado y, por tanto, con centralización del excedente.

2 Se utiliza el término etnicista para designar a quienes, en función de revalorar, mistifican de manera acrítica todo lo referente a las sociedades étnicas, atribuyéndoles solo características positivas, y muestran ceguera hacia las negativas.

3 Cuando las formas de trabajo asalariado atraen e invitan a la migración de la población hacia lugares lejanos, las comunidades contabilizan el tiempo de trabajo que «deben» los migrantes y que habrán de pagar en algún momento. Las formas de cobro recurren a ingeniosos sistemas, como reclamar el pago cuando se requiere algún tipo de servicio comunitario, por ejemplo, la expedición de actas de nacimiento. 
Si bien las formas de trabajo comunitario pueden ser cuestionadas en tanto lesivas de los derechos individuales, no se puede negar que estas persisten, al menos en gran parte de las comunidades indígenas de México; sin embargo, la suposición en cuanto a la existencia de formas de propiedad colectiva o a la repartición igualitaria del excedente no puede ser generalizada. Si bien persisten en el país espacios o formas de propiedad que se reconocen como comunes, el acceso a la tierra de cultivo suele presentar la forma de apropiación familiar y sujeta a cuidadosas regulaciones de herencia. ${ }^{4}$ Como argumento a favor de la distinción entre estos espacios es que fracasaron rotundamente los intentos de colectivización de la producción agrícola inspirados en los modelos soviéticos. De allí la necesidad de realizar investigaciones exhaustivas, y ajenas a las simplificaciones apologéticas para investigar cuáles aspectos de la vida social pueden o han sido objeto de prácticas socializadoras y cuáles suponen la apropiación individual y familiar, para no caer en esquemas simplificadores como los que proponen colectivizar todo o privatizar todo. La etnografía ha sido pródiga en la documentación de espacios exclusivos, para un género o grupo, de la existencia de bienes no transferibles y de su simbolización por medio de tabús y restricciones fundadas en el mito y el ritual, y en cuanto a la multiplicidad de formas de apropiación: la casa que puede ser compartida pero no transferible o vendible; la existencia de la mano vuelta como mecanismo recíproco de trabajo, u otros como los derechos de monte, por tradición colectivos, pero que no dejan de representar arenas de conflicto cuando la lógica de la ventaja monetaria se introduce en las comunidades, o en algunos de sus miembros. En cuanto a la repartición igualitaria de excedentes tampoco puede ser generalizada, como hacen los autores, en tanto que si no existe producción colectiva tampoco hay excedentes colectivos, y cuando estos existen —caso de los derechos de monte- suelen ser objeto de complejos mecanismos de redistribución, entre los que se encuentran los sistemas de fiestas (Smith 1981). En todo caso habrá que reconocer, como proponen Mauss (1979) y Godelier (1998), entre otros, la existencia de múltiples formas de posesión o propiedad.

Independientemente de la veracidad u objetividad de los datos aportados por quienes mistifican a las comunidades originarias de América, la existencia de la noción de buen vivir como patrimonio cultural colectivo pareciera implicar una distinción sustantiva. Los autores señalan la importancia de su incorporación

\footnotetext{
4 Véase, por ejemplo, el cuidadoso estudio sobre la herencia entre los tsotsiles, realizado por el equipo coordinado por Collier (1975).
} 
en la Constitución de Ecuador en 2008, y en la de Bolivia en 2009 (Chiroque y Mutabarria 2009). La noción de buen vivir o buena vida supondría un cambio de óptica con respecto a los criterios cuantitativos que suelen manejar los economistas como el de producto interno bruto (PIB), que solo considera indicadores de crecimiento de la producción manejados en términos monetarios. Contrariamente, el buen vivir supone incorporar elementos intangibles referidos a la cultura, sobre todo al sistema de relaciones sociales, pero también la satisfacción de necesidades de manera social o individual sin la obligación de recurrir al mercado, como las esferas de la recolección, la autosubsistencia y la producción doméstica; en esta última categoría no considero exclusivamente las llamadas actividades de traspatio, sino también lo que ha sido denominado la economía o el trabajo invisible. Algunas feministas han demandado la contabilización del trabajo invisible y su incorporación a la cuenta pública, como parte del PIB, así como su retribución pecuniaria; de hacerlo así se estaría mercantilizando uno de los pocos reductos de la reciprocidad. Y el cambio de los indicadores de buen vivir podría representar una transición hacia la revalorización de los aspectos solidarios y recíprocos de la economía.

Otro aspecto que puede ser cuestionado cuando se mistifican las culturas aborígenes son las supuestas conductas democráticas. Generalmente los apologistas tienden a magnificar el contenido democrático de las votaciones en asamblea y de la adhesión colectiva a determinadas propuestas, que esconden lo que Touraine considera dictadura comunitaria (1997). La fórmula que recurre a los usos y costumbres, considerada en la actualidad como políticamente correcta y está incorporada como progresista en constituciones nacionales y regionales, ${ }^{5}$ esconde problemas de respeto de las minorías e incluso de la mayorías, como los derechos de las mujeres. Valga como ejemplo el caso de Eufrosina Mendoza, candidata electa a la presidencia de Santa María Quiegolani, municipio de Oaxaca, a quien le impidieron tomar posesión pues los varones consideraron que atentaba contra los usos y costumbres que una mujer detentara el poder. ${ }^{6}$ Si bien este caso figuró en la prensa nacional e internacional por la voluntad de la candidata de recurrir a la Corte Internacional de Derechos Humanos en La Haya, la limita-

${ }^{5}$ Utilizo el término regional como genérico que incorpora la noción de estados y la de provincias o distritos.

6 De acuerdo con lo expresado por Eva Olivera, integrante del grupo de mujeres que dio a conocer el hecho en la Cámara de Diputados, Cruz Mendoza fue candidata a la presidencia municipal de Santa María Quiegolani para el trienio 2007-2009. Sin embargo, después de las votaciones, su candidatura fue desconocida, «dicen que por usos y costumbres las mujeres no participan, no tienen derechos y se ve muy feo que estén en las asambleas» (La Jornada, 22 de diciembre de 2007). 
ción de los derechos de las mujeres en las comunidades tradicionales aparece de manera generalizada. La democracia de la decisión comunitaria, además de establecer fronteras de género, suele implicar problemas en cuanto a la libertad de decisión, contrarios a la imagen de democracia occidental que supone el voto secreto. Esta condición, por lo demás, resulta difícil de sostener en comunidades pequeñas y territorializadas. Se puede coincidir con los autores que insisten en las economías comunitarias, reductos de relaciones y lógicas de reciprocidad y redistribución, que requieren ser revalorados, lo cual puede hacerse desde una perspectiva ecuánime, sin necesidad de mistificar, aunque en el lenguaje de la prédica política se pueda recurrir a la exaltación. La ecuanimidad que menciono —evitando recurrir al concepto de objetividad, severamente cuestionado-, tiene el sentido de descartar las simplificaciones, que pueden ser fatales para las ideologías políticas, sobre todo cuando llegan al poder.

\section{EL BUEN VIVIR COMO LÓGICA}

Acceder a la lógica, al motor que anima el resto de las relaciones, no resulta tarea sencilla. Marx, uno de los acuciosos críticos del capitalismo, creyó encontrar el núcleo duro en la propiedad privada de los medios de producción y, en consecuencia, al igual que los socialistas utópicos, propuso su socialización. En opinión de Žižek este diagnóstico identificó el síntoma y no el trauma (2003), yo agregaría que vio el objeto de la cultura y no la lógica implícita. La propiedad privada solo fue un componente, en este caso jurídico. Sin embargo, es preciso reconocer que Marx (1968a) también describió extensivamente la lógica del capitalismo: la reproducción ampliada de capital, y el tránsito de la fórmula M-D-M a la de C-M-C, solo que no le dio la importancia central. En el caso de los pueblos originarios de América, así como en muchas sociedades campesinas de otras partes del mundo, el componente central del modelo sería la lógica reproductiva (Hinkelammert 2009) o, como le denomina Coraggio (2009), la reproducción social ampliada, donde la diferencia radica en que el fin de la producción se centra en la satisfacción de las necesidades humanas o, en palabras de Polanyi, el sustento del hombre (2009) y no la acumulación de riqueza.

La lógica reproductiva tendría por tanto como característica que toma de la naturaleza aquello que va a consumir, con el suficiente excedente para prevenir la escasez, o para el gasto festivo-ceremonial e incluso suntuario. Por tanto, el esfuerzo invertido es proporcional al punto donde se logra lo requerido y no más. 
Desde la antropología económica y otras disciplinas confrontadas con la realidad se han datado ejemplos de la existencia de una lógica reproductiva. Cuando Chayanov (1966) descubre la lógica de los campesinos rusos se sorprende y no deja de considerarla poco avanzada; sin embargo, demuestra a partir de la datación empírica que:

[...] la unidad campesina constituye una unidad de producción y consumo; de que la producción y reproducción social y económica, ocurre al interior del grupo familiar y que el objetivo primordial de la producción campesina es la satisfacción de las necesidades de consumo y no el lucro [...] emplea sus propios recursos laborales, nunca compra trabajo (Palerm 1997).

Si la conducta campesina fue motivo de sorpresa en su momento, en algunos de los ejemplos etnográficos, la ironía recaería sobre el comportamiento económico occidental, al menos así se intuye en el texto etnográfico que Lee (1981) denomina un análisis in-put, out-put. Retomando las categorías de la economía política demuestra que los bosquimanos kung satisfacen con creces sus necesidades de alimentación dedicando solo un tercio de los días del año al trabajo y el resto al ocio y el esparcimiento, con lo cual resultan bastante más eficientes que nosotros, los occidentales.

En la obra clásica de Weber sobre la ética protestante aparecen varios ejemplos de lo que denomina el pensamiento económico tradicional, uno de un empresario y el otro de un obrero, que demostrarían la vigencia de la lógica reproductiva, a finales del siglo XIX, en Europa. Su persistencia en el mundo campesino fue datada por Meillassoux (1977), que definió su forma organizativa en términos de unidad doméstica (UD), también por Archetti y Stölen (1975) para los agricultores de Argentina.

La existencia de una lógica diferenciada que orienta la producción lleva a Godelier (1967) a proponer la necesidad de preguntar por los fines de la actividad económica, para distinguir entre el fin de lucro y el que se orienta a satisfacer las necesidades. La existencia de diferentes móviles para la producción llevó a Polanyi a buscar una definición sustantiva de la economía, que se aplicara a las diferentes formas concretas, pero también común a los motivos que orientan la producción. La definición que denomina sustantiva supone un proceso institucionalizado que sirve para la satisfacción de las necesidades materiales (y sociales se podría agregar) que implica una interacción de los hombres entre sí y con su entorno (Polanyi 2009). La definición sustantiva, meridianamente clara y sintética, 
lleva implícitos los componentes o las variables para definir cada modelo: en primer lugar cuáles son las necesidades a satisfacer, en consecuencia, cuál es el tipo de relación que se establece con la naturaleza, y las formas de relación entre las personas.

El primer componente, el de los fines, lleva a la revisión de la teoría de las necesidades humanas — Hegel (en Cohen y Arato 2002 ), Marx (1968b), Arendt (1958), Nussbaum (2002), Boltvinik (2007)_, para discutir cuáles son las necesidades humanas a satisfacer y sobre todo si pueden limitarse a las necesidades materiales, como parecen presuponer los economistas cuantitativistas, o imponerse una jerarquía en cuanto a su prioridad, como proponía Maslow (1998). Mientras que varios de los autores coinciden en que las necesidades humanas aparecen como invariables, otros abogan por su relatividad. Marx, por ejemplo, menciona la capacidad civilizadora del capital (1968a) por su capacidad de generar necesidades; habría que ver si coincidiría con tal afirmación en tiempos de consumismo. La posición contraria supone que las necesidades permanecen invariables y colocan la relatividad en los satisfactores a los que se recurre. Pero la creación de necesidades artificiales no es privativa del capitalismo, se encuentra en la mayoría de las sociedades estatales, aun en aquellas en cuya base seguían operando con la lógica reproductiva. La necesidad de ejércitos, de lugares de culto, de palacios, llevando a mecanismos de extracción de excedentes.

La relación con la naturaleza diferencia las posiciones extractivistas de aqueIlas que, como en la definición de Chiroque y Mundeberria (2009), establecen reciprocidad con la naturaleza. En términos de representaciones, depende de la definición de la naturaleza: si se ve como objeto o como ente viviente. Cuando la naturaleza es observada y definida como un objeto inerte, la actitud resultante conduce al extractivismo y demás actitudes depredadoras. En cambio, la visión que concede agencia a la naturaleza, que la sacraliza —concepción que los primeros antropólogos calificaron como animista-, implica la interacción hombre-naturaleza. Bajo tal concepción a la naturaleza hay que pedirle, ofrendarle, tratarla con amabilidad. Sin necesidad de divinizarla, se puede partir por considerar a los seres humanos parte de la naturaleza y no sus amos. En la medida en que las representaciones no constituyen solo una idea, sino una forma de ver-juzgar-actuar, condicionan la actitud y la conducta, establecen un sistema de relaciones del hombre con la naturaleza.

En cuanto a la relación entre las personas, toca en parte — solo en partea lo que Marx (1968a) denominó las relaciones sociales de producción, y sosten- 
go que en parte pues para representar la compleja realidad de las relaciones sociales, no pueden limitarse al concepto de producción, sino que en todo caso sería de reproducción. Por una parte, se encuentra el hecho de que la producción se limita a un momento del ciclo, complementado por la circulación y el consumo, como etapas no separables, integradas por una lógica común; en Marx sería la identidad consumo-producción (1968a). Por otro lado, en la mayoría de las sociedades prepositivistas resulta imposible distinguir la infraestructura de la superestructura, como demostró Godelier (1977), pues la economía se encuentra encastrada en la sociedad (Polanyi 2006). En relación con la circulación, Polanyi propone la existencia de lo que denomina los tres principios de integración: la reciprocidad, la redistribución y el mercado, que permiten la circulación de bienes y personas. La primera opera de acuerdo con la lógica del don, como la denominó Mauss, que implica una triple obligación, la de dar, la de aceptar y la de devolver (Mauss 1979). La redistribución implica un centro que recaudación, es decir, algún tipo de autoridad o poder estatal, mientras que el mercado requiere mecanismos formadores de precios. Comienzo con los dos últimos para dedicar más espacio a la reciprocidad, pues es la que refuerza la interdependencia y por tanto fortalece los lazos locales. La redistribución se produce cuando alguien, un ente, una institución, concentra productos o dinero para luego redistribuirlos. Es el mecanismo por excelencia de las sociedades estatales. En el México prehispánico y los primeros tiempos de la colonia operó mediante tributos. En las sociedades modernas recurre a la recaudación de impuestos que, se supone, el Estado devuelve en forma de servicios: la salud pública, la educación pública, pero también la recolección de basura, el alumbrado o las obras de infraestructura. Su operación tiende a requerir pesadas burocracias, que son las que finalmente deciden los criterios de la redistribución, ya en lo tocante a las formas y calidad de los bienes, como en lo relativo a los mecanismos de compensación, como trasladar recursos de quienes más tienen a quienes más lo necesitan, en función de criterios de equidad. Su máxima expresión, en tiempos recientes es el llamado Estado de bienestar, que supuestamente garantizaba la satisfacción de todas las necesidades de los habitantes. Su principal problema es la burocratización, la delegación y la consecuente desresponsabilización e involucramiento de las personas en los asuntos que les competen, con la consecuente sensación de vacío, de alienación. Para entender estas ideas basta con acudir a la imagen del burócrata. La relación de intercambio de mercado se realiza mediante el establecimiento de precios. Supone una transacción entre dos, en la que se intercambia un bien 
o servicio que se paga con un medio de intercambio, generalmente el dinero, que salda la relación. La actividad de intercambio bajo este sistema tiene como fin obtener alguna ventaja. Los precios, si bien responden a la ley de la oferta y la demanda, tienen como base el costo de producción más eficiente (Dobb 1975).

Si la redistribución genera burocracia y desinterés, el mercado especulación y lucro, la reciprocidad teje relaciones sociales e interdependencia. La reciprocidad constituye una fórmula de circulación de bienes, que si bien sufre los embates del mercado, aún persiste aunque no como mecanismo institucionalizado 7 pero sí en las relaciones cotidianas. Polanyi la define como: «movimientos entre puntos correlativos en grupos simétricos» (2006:162). En palabras sencillas consiste en un regalo, un don que se concede a otro y que genera en quien lo recibe la tendencia a devolverlo, aunque no sea en el mismo tiempo o lugar. Ejemplos de relaciones de reciprocidad en la vida cotidiana abundan. Los regalos de cumpleaños, los intercambios en Navidad, o los de boda. Estos intercambios obtienen la forma de trueque cuando suponen un acuerdo. En México persisten formas institucionalizadas de reciprocidad, como la mano vuelta. Un componente de las relaciones no monetizadas es la noción de equivalencia. La equivalencia (Polanyi 2009) supone asignar valor a cosas distintas para que puedan ser intercambiadas, con criterios diferentes a los del precio. El precio tiene como referencia las leyes de la oferta y la demanda y como punto de partida —aunque no únicoel menor costo. El producto más barato establece la pauta para los restantes. La equivalencia, es un acuerdo, que no necesariamente toma en consideración el costo de producción o la eficiencia. La equivalencia, aunque pueda implicar complejos mecanismos de asignación, posibilita escapar a la noción de precios, es más, históricamente le antecede. El criterio puede ser que costaron el mismo tiempo de trabajo, o que son igualmente necesarios. Estos intercambios pueden considerar el tiempo invertido, pero no necesariamente tienen que recurrir a cálculos abstractos y pueden apelar simplemente a considerar qué se necesita, es decir, aplicar el sentido común. Los gobiernos aplican criterios de necesidad, por encima del de costo de producción, por ejemplo, cuando establecen un precio máximo a productos de necesidad, generalmente mediante subsidio. El sentido de equivalencia puede constituir la referencia del trueque, del comercio con algún medio de cambio (no necesariamente dinero convencional), pero también opera en la reciprocidad. Por último, el acto de fiar, así como los préstamos entre

7 Estudios etnológicos en diferentes partes del mundo han descrito casos en los que la reciprocidad constituye el mecanismo principal de la circulación de bienes. 
vecinos se inscriben en las relaciones no mercantiles en dos sentidos: conservan la reciprocidad -recibo un préstamo / debo prestar-, pero lo hacen mientras se encuentren exentas del cobro de interés. Esta es la gran diferencia, por ejemplo, entre las tandas tradicionales, donde mediante la aportación de los participantes se acumula un fondo que se reparte por vez, mediante sorteo, hasta que todas las participantes recibían su tanda, respecto de las microfinancieras, que cobran interés y obligan a pagar más por lo recibido. Todos estos mecanismos crean sociedad (Godelier 1989), refuerzan los lazos entre personas, familias o amigos, sirven para satisfacer necesidades afectivas, pero también porque el individuo no se siente ni se encuentra solo, pero sobre todo para resolver los problemas vitales: las personas se hallan inscritas en entramadas redes de solidaridad, a las que se puede recurrir o que simplemente estarán ahí. El éxito de los migrantes se ubica en estas redes, que investigadoras como Larissa Lomnitz (1975) y Úrsula Oswald (1991) calificaron como estrategias de supervivencia. En mi opinión la expresión guarda un cierto dejo descalificatorio, pues al juzgarlos de ese modo y al completar —Lomnitz- la idea con el concepto de marginados, pareciera asignar estas redes de solidaridad exclusivamente a los pobres o como propias de pobres; por tanto prefiero denominarlas estrategias sociales, redes que crean sociedad y cadenas permanentes de intercambios de favores y dones. La idea de devolver lo recibido, decíamos, teje sociedad, pues las relaciones en vez de impersonales, adquieren nombre y, sobre todo, se reproducen en el tiempo. Contrariamente, en la sociedad de mercado los intercambios se realizan mediante un pago en dinero, que cancela definitivamente la deuda y no generan contraprestación, no componen tampoco sociedad de allí, que el individuo autónomo sea su arquetipo. En la definición propuesta por Polanyi se incluye el componente de intercambios entre puntos simétricos, pues cuando la idea de devolución o contra-don se realiza entre no iguales o no simétricos puede presentar un componente perverso. La idea de devolver el favor se encuentra como componente del clientelismo, donde —recurriendo a un ejemplo burdo-quien recibe un regalo de un candidato se siente obligado a concederle el voto (Auyero 1997). El clientelismo, el caciquismo y la operación de muchas organizaciones políticas y sindicales manipula estas lealtades primordiales (Alavi 1976), cuando enfatizan o hacen sentir que conceden a sus partidarios las cosas como favor y no como derecho. Los líderes lo manejan deliberadamente, cuando dicen: me lo debes; el supuesto favor suele cobrarse con favores políticos, tanto el voto como la incondicionalidad y el acarreo. 
Las diferencias implican, en términos de relaciones entre personas, percepciones diferentes: la reciprocidad supone la existencia de relaciones horizontales. Polanyi hace referencia a puntos simétricos, y cuando se le superpone una estructura jerárquica, se convierte en clientelismo (Alavi 1976); la redistribución se inserta en relaciones jerárquicas, verticales, generalmente paternalistas, mientras el mercado entra en la categoría de abstracto. Los tres pueden operar simultáneamente en una misma sociedad; de hecho así ha sucedido, pero en determinados momentos uno aparece como dominante. En este momento el mercado resulta dominante, e intenta atraer todos los intercambios a su lógica; por eso procura mercantilizarlo todo, la cultura transformada de patrimonio en industria cultural (Yañez 2006), la naturaleza en turismo ecológico, la diversión en industria de entretenimiento, los alumnos en clientes; en una palabra, la «macdonalizacion» de la sociedad (Ritzer 2005).

En cuanto a las formas de organización del trabajo, históricamente aparecen como posibles el trabajo autónomo, el esclavizado y el asalariado, correspondiendo igualmente a relaciones horizontales, verticales o abstractas.

\section{LA LÓGICA REPRODUCTIVA Y LOS PUEBLOS INDIOS EN MÉXICO}

Si se acepta la existencia de una lógica reproductiva, que implica como fin de la actividad económica la satisfacción de necesidades, donde las relaciones entre las personas y con la naturaleza se basan en principios de reciprocidad, habrá que analizar si los sistemas de representaciones y las prácticas de los pueblos indios coinciden con esos criterios. En ese caso la idea nativa del buen vivir resultaría equivalente a la lógica reproductiva, y por tanto un modelo de reproducción social. La carencia de estudios específicos orientados a identificar las lógicas implícitas en las actividades de reproducción social puede subsanarse, infiriendo preferencias y valores a partir de la datación etnográfica previa. Varios de los temas abordados por los antropólogos en alusión a las prácticas de los pueblos indios y su permanencia parecieran indicar que presuponen una escala de valores. Al menos tres temas recurrentes en la etnografía dan cuenta de aspectos de las lógicas que animan la cultura tradicional: los sistemas de fiestas, la persistencia de la familia extensa con gasto compartido y el sistema milpa.

El complejo sistema ritual y festivo ha sido y es objeto de múltiples descripciones etnográficas y motivo de intentos de explicación. Sin entrar a discutir las teorías respectivas, resulta evidente que la compleja organización ritual teje un 
entramado de relaciones sociales orientadas tanto a mantener sistemas festivos como a construir redes de reciprocidad y parentesco ficticio. Redes que inciden también en otros ámbitos y que con cierto dejo peyorativo han sido interpretadas como estrategias de supervivencia (Lomnitz 1975, Oswald 1991). La persistencia de los sistemas de fiestas indica una preferencia: la de dedicar tiempo a las actividades sociales y el esparcimiento. Elección que se privilegia por encima de la laboral, o la obtención de dinero. La valoración del espacio festivo y las relaciones sociales, por encima de las destinadas a recibir ingresos, ha sido motivo de crítica e incomprensión, ignorando que el afecto y el esparcimiento constituyen necesidades humanas tan básicas como la alimentación y las redes de relaciones, un recurso de vida que algunos mercantilizan al definirlo como capital social (Bourdieu 1987). El ritual se asocia con las representaciones de lo sagrado, y en este campo la persistencia de un cierto animismo mantiene - aunque de forma disminuida - relaciones de reciprocidad y negociación con la naturaleza, que inciden en la conservación de recursos naturales como el bosque y los manantiales (Boege 2008).

La familia extensa con gasto compartido no es otra cosa que la unidad doméstica descrita páginas arriba, donde los diferentes miembros de la familia colaboran a la reproducción del grupo familiar, sin que existan relaciones salariales al interior, y si existen al exterior, de cualquier forma parte del ingreso se suma al gasto conjunto. Se entiende en este marco el envío de remesas por parte de los migrantes. Esta modalidad, propia de las sociedades campesinas, con división sexual y generacional del trabajo, se traslada al medio urbano, sobre todo en las actividades comerciales y artesanales, para establecerse como la modalidad propia de la economía popular según Coraggio (2003) y Razetto (1988). La ausencia de relaciones salariales y, por tanto, de registro formal ante instancias fiscales y de seguridad social, facilita que, desde la visión moderna, sean descalificados al considerarlos economía informal. La crítica emana de una visión cerrada que solo contempla como trabajo válido el empleo y las relaciones salariales. La UD constituye una forma de organización y división del trabajo que si bien puede ser cuestionada por mantener estructuras patriarcales, también es cierto que la flexible organización de tiempo y esfuerzo permite a sus miembros cumplir con otros fines extralaborales: de estudio, deporte o esparcimiento; maximiza los ingresos por incorporarse a un gasto compartido y minimiza los egresos por compartir la infraestructura doméstica. 
El tercer elemento, que apunta a la existencia de una lógica económica diferenciada, es el llamado sistema milpa, base de la subsistencia mesoamericana desde tiempos inmemoriales y en franco retroceso a partir de la acción misionera de extensionistas y promotores del desarrollo, empecinados en implantar el monocultivo. La base del sistema milpa es la biodiversidad y por tanto la interdependencia. En la milpa se combinan especies vegetales que conviven con la fauna, desde insectos hasta animales domésticos. El resultado suele ser que en una superficie pequeña se obtienen productos diversos por lo general destinados al autoconsumo y a proporcionar una dieta variada (Barkin 2004, Toledo 2008). La orientación a la autosuficiencia fue devaluada y considerada como marginal. Los productos de autoconsumo no se consideraron como ingresos y por tanto a sus consumidores se les calificó como pobres.

En realidad, el sistema milpa se opone al monocultivo, no solo por los fines que persigue — producción de mercancías o bienes de uso—, sino en términos de lógica. Una lógica de la diversidad, la interdependencia y la mezcla, propia de la naturaleza, contra la lógica de la especialización, la separación en compartimentos estancos, y de la hibridación del pensamiento moderno, y la creencia en la ingeniería social a gran escala. Bauman (2005) califica esta última como la lógica del jardinero, que quita las malezas y modela a la naturaleza con criterios de orden formal. Esta lógica extendida a la sociedades se expresa en la necesidad entre los occidentales de domesticar a los otros, cuando no de exterminarlos. Al orden casi matemático de los jardines occidentales se opone el desorden crónico de la milpa, donde la convivencia de organismos ha dado lugar a la polinización cruzada y el surgimiento de nuevas razas y clases. La metáfora del jardinero contrapone las culturas cultivadas, producidas, dirigidas y diseñadas por una parte y las culturas silvestres o «naturales» por la otra.

$\mathrm{Si}$ interpretamos estos patrones culturales en términos de lógica se puede inferir la valoración de la diversidad y de la interdependencia, entre las personas y con la naturaleza, la consideración de la actividad económica como parte de las relaciones sociales, ${ }^{8}$ así como la valoración del tiempo dedicado a las relaciones sociales y el esparcimiento. En términos de finalidad destaca la orientación del esfuerzo a la obtención de los bienes necesarios para la reproducción social.

8 Polanyi (2006) considera las actividades económicas embeded, en las relaciones sociales. El termino embeded va más allá de la idea de formar parte, una parte puede ser separada del todo en cambio embeded supone una relación intrínseca. 


\section{A MANERA DE CONCLUSIÓN}

El tema del buen vivir ha captado un interés creciente a partir de su inclusión en las legislaciones de Bolivia y Ecuador y en consecuencia ha pasado a ser motivo de análisis y discusión. Las posiciones divergen en cuanto a lo que representa su uso desde la perspectiva del cambio social y cultural. Una primera división se presenta entre quienes desde el punto de vista emic utilizan el discurso del buen vivir como elemento diferenciador en la construcción de la otredad, en oposición a Occidente, y en la otra vereda se encuentran quienes pretenden abordar la conceptualización de la propuesta étnica en términos académicos. No sin contradicciones y resemantizaciones en el tránsito de un plano al otro, como señalan Vanhulst y Beling (2013). En esta segunda vertiente no faltan los intelectuales indios, algunos de ellos doctorantes en países extranjeros (Mamani-Ramírez 2011).

La construcción conceptual pareciera seguir caminos divergentes. Una primera orientación reinterpreta el concepto étnico desde la óptica del Estado de bienestar y en consecuencia pretende transformarlo en políticas públicas redistributivas, ya en versiones cercanas a la socialdemocracia (Acosta 2011, Féliz 2011, Gudynas y Acosta 2011, Houtart 2011, Manosalvas 2014, Ramírez 2010) o más radicales, con el atributo de socialistas (Hendel 2011, Le Quang y Vercoutère 2013, Antunes y Braga 2011). Por su prolífica pluma destaca Alberto Acosta, quien fungiera como presidente de la Asamblea Constituyente del Ecuador, y como ministro de Energía y Minas, para luego asumir una posición crítica frente al gobierno de Correa. La conciliación entre el esquema emic vinculado - por casi todos los autores - a estructuras horizontales de reciprocidad, con las políticas estatales que por definición son de redistribución del centro a la periferia, o en términos más sencillos de estructura vertical, parece una tarea ardua, si no imposible —contradicción señalada con precisión por Gudynas (2011)—; de allí que los autores de esta corriente prefieran centrase en el problema ambiental, y dejar de lado la lógica productiva. La vertiente crítica señala la posible existencia de ventrilocuismo (Zaldívar 2013).

Una segunda tendencia asume el tono moral, propio del discurso religioso para reinterpretar el sentido del buen vivir en términos de valores que atañen a las relaciones entre los seres humanos como solidaridad y reciprocidad (Medina 2011, Bautista 2011), el cuidado (Medina 2011, García-Álvarez 2014), miradas ontológicas como la complementariedad (Medina 2011, Bautista 2011), y en especial las ideas que aluden a la consideración de la naturaleza como ser vivo (Bautista 2011, 
Mamani-Ramírez 2011, Féliz 2011, Sejenovich 2011). El defecto de la visión desde los valores radica en lo que podríamos llamar su subjetivismo, donde el cambio corresponde a la elección valorativa de las personas.

La tercera, con la que coincido, es la que reinterpreta el buen vivir en términos de una lógica o racionalidad cultural (Albó 2011, Hendel 2011, Galafassi 2010) que imprime a la conducta el sentido de la reproducción de la vida y de la satisfacción de necesidades (Antunes 2011). La lógica reproductiva (Hinkelammert y Mora 2008) se vincula a la autosuficiencia y la autonomía - que no autarquíay con los espacios locales-regionales (Unceta 2014, García-Álvarez 2014, Collin 2014, Zibechi 2010), aunque puedan ser discontinuos y en diferentes nichos ecológicos, entendidos como comunitarismo (Medina 2011) y con el socialismo comunitario (Santos 2012). Nivel de autonomía contradictorio con el esquema estatal redistributivo. Esta mirada, que interpreta el buen vivir como sistema de pensamiento, encuentra estructuras semejantes en culturas orientales y africanas (Albó 2011, Vanhulst y Beling 2013, Mamani-Ramírez 2011, Unceta 2014, Medina 2011) a las que pueden agregarse las europeas precapitalistas como las que describe Chayanov. La perspectiva cultural suele vincularse con el señalamiento de la existencia de una crisis civilizatoria (Bautista 2011, Féliz 2011), la crítica del desarrollo (Mamani-Ramírez 2011, Gudynas 2011, Gudynas y Acosta 2011), el maldesarrollo (Tortosa 2009), la caducidad del paradigma cartesiano (Albó 2011) y la emergencia de nuevos esquemas de pensamiento (Romero 2011, Medina 2011). Si bien, con funciones expositivas, intento sistematizar y diferenciar las posiciones; en los textos las posiciones no son tan claras, y quienes realizan propuestas distributivas, de igual manera, mencionan el cambio de paradigma, o aluden a los valores, indicando la existencia de un conjunto de búsquedas que consideran posible un mundo más allá del capitalismo, u otros mundos, y que esa forma de verlo ha existido previamente y puede volver a aparecer.

Una nueva mirada que compare las lógicas del buen vivir y de la comodidad en términos de la satisfacción de necesidades podría cuestionar la autorrepresentación de satisfacción del occidental consumista. Mientras la lógica occidental pareciera reconocer solo las necesidades materiales, la idea del buen vivir se muestra más equilibrada. Al parecer, por el tiempo y la energía que se dedican a satisfacer las necesidades emocionales y de estima, estas se encontrarían plenamente cumplidas, al igual que las creativas, dado el vínculo que se mantiene con la naturaleza y con el producto del trabajo. Cabría dedicar más atención a las necesidades cognitivas, pues si bien la literatura antropológica recalca la cues- 
tión de los saberes tradicionales, tantos años de su sistemática devaluación seguramente surtieron efecto; tampoco debe dejarse de lado la denominada tiranía comunitaria (Touraine 1997), que desalienta el pensamiento crítico o disidente.

La modernidad, en sus diferentes etapas, ha tendido a privilegiar la obtención de dinero —riqueza, en Adam Smith (2004); el crecimiento o el PIB, en las versiones de los organismos internacionales actuales- sobre cualquier otra actividad, así como a transferir la satisfacción de necesidades al mercado, donde se compra algún bien o servicio. Contrariamente, en las economías tradicionales la mayoría de las necesidades son satisfechas de manera autogestiva y por participación social, tanto de los miembros de la UD como de la comunidad y, hasta fechas recientes, no implicaban costo en dinero. De hecho, hasta el momento solo la satisfacción de las necesidades básicas o de supervivencia parecen depender del mercado y, por tanto, del dinero. Desde una perspectiva moderna son cada vez mayores las necesidades que se transfieren al mercado, y en muchos casos se adquieren sustitutos pobres de la verdadera satisfacción — sexo en vez de amor, contactos en vez de amigos, fastfood en vez de comida, guardería en vez de abuela_. Por otra parte, la lógica de la reproducción ampliada del capital se extiende a los actos de consumo, con el «más es mejor», donde la apología de lo grande y abundante sustituye la satisfacción. La lógica de la suficiencia parece ir en sentido opuesto. Foster, no sin dejo crítico, señalaba que «buena parte de la conducta se puede explicar si se considera como una función del presupuesto de que casi todas las cosas buenas de la vida existen en cantidad pequeña y limitada» (Foster 1972). A la idea de suficiencia Illich la denomina austeridad convivial (Illich 2006).

La idea de buen vivir que persiste como sustrato cultural en muchos pueblos originarios de América, por debajo de las diferencias de grado, de los artefactos culturales y de las condiciones sociales concretas, lleva implícita una lógica reproductiva que privilegia la reproducción social como fin, valora los aspectos relacionales y simbólicos de la vida, mantiene relaciones de reciprocidad con la naturaleza y puede representar un modelo civilizatorio.

\section{FUENTES DE CONSULTA}

Acosta, Alberto, 2011, «Sólo imaginando otros mundos, se cambiará éste. Reflexiones sobre el Buen Vivir», en Ivon Farah y Luciano Vasapollo (coords.), Vivir bien:¿Paradigma no capitalista?, La Paz, Universidad de Roma/CIDES-UMSA/OXFAM, pp. 189-208. 
Alavi, Hamza, 1976, «Los Campesinos y las lealtades primordiales», en Eric J. Hobsbawn y Hamza Alavi, Los campesinos y la política. Las clases campesinas y las lealtades primordiales, Barcelona, Anagrama.

Albó, Xavier, 2011, «Suma qamaña = convivir bien. ¿Cómo medirlo?» en Ivon Farah y Luciano Vasapollo (coords.), Vivir bien:¿Paradigma no capitalista?, La Paz, Universidad de Roma / CIDES-UMSA/OXFAM, pp. 133-142.

Antunes, Ricardo y Ruy Braga, 2011, «Para un nuevo estilo de vida en América Latina: orígenes básicos de otro sistema del metabolismo social», en Ivon Farah y Luciano Vasapollo (coords.), Vivir bien:¿Paradigma no capitalista?, La Paz, Universidad de Roma / CIDES-UMSA/OXFAM, pp. 159-168.

Archetti, Eduardo P. y Kristi Anne Stolen, 1975, Explotación familiar y acumulación de capital en el campo argentino, Buenos Aires, Siglo XXI Editores.

Arendt, Hannah, 1958, The Human Condition, Chicago, University of Chicago Press.

Auyero, Javier, 1997, ¿Favores por votos?: estudios sobre clientelismo político contemporáneo, Buenos Aires, Losada.

Baéz-Jorge, Félix, 1978, «Aculturación e integración intercultural: un momento histórico del Indigenismo Mexicano», en INI 30 años después. Revisión Crítica, México, INI, pp. 290-299.

, 1979, «La participación política y los grupos étnicos en México», Revista Mexicana de Ciencias Políticas y Sociales, 97, pp. 41-81.

Barkin, David, 2004, «La soberanía alimentaria: el quehacer del campesino mexicano», Estudios Agrarios, 22, pp. 35-65.

Bauman, Zygmunt, 2005, Modernidad y Ambivalencia, México, Anthropos / UNAM / UCV.

Bautista, Rafael, 2011, "Hacia una constitución del sentido significativo del "vivir bien"», en Ivon Farah y Luciano Vasapollo (coords.), Vivir bien:¿Paradigma no capitalista?, La Paz, Universidad de Roma / CIDES-UMSA/OXFAM, pp. 93-124.

Boege, Eckart, 2008, El patrimonio biocultural de los pueblos Indígenas de México. Hacia la conservación in situ de la biodiversidad y agrodiversidad en los territorios indígenas, México, Comisión Nacional para el Desarrollo de los Pueblos Indígenas.

Boltvinik, Julio, 2007, «Elementos para la crítica de la economía política de la pobreza», Desacatos, 23, pp. 53-86.

Bonfil Batalla, Guillermo, 1995, «El etnodesarrollo. Sus premisas jurídicas, políticas y de organización», en Obras escogidas, México, INAH / INI, pp. 464-480.

Bourdieu, Pierre, 1987, Cosas dichas, Barcelona, Gedisa.

Cattani, Antonio David, José Luis Coraggio y Jean-Louis Laville (organizadores), 2009, Diccionario de la otra economía, Buenos Aires, UNGS / Altamira / CLACSO.

Chayanov, Alexander V., 1966, The Theory of Peasant Economy, Illinois, The American Economic Association.

Chiroque Solano, Henry y Valeria Mutuberria, 2009, «Economía Comunitaria», en Antonio David Cattani, José Luis Coraggio y Jean-Louis Laville, (organizadores), Diccionario de la otra economía, Buenos Aires, UNGS / Altamira / CLACSO, pp. 121-133.

Cohen, Jean L. y Andrew Arato, 2002, Sociedad civil y teoría política, México, FCE.

Collier, George, 1975, Planos de interacción del mundo tzotzil, México, INI. 
Collin, Laura, 2003, «Nuevos Liderazgos Indios», en A. Colatarcci (comp.), Folklore Latinoamericano, t. I, Buenos Aires, Instituto Nacional Superior del Profesorado de Folklore-IUNA, pp. 377-390. , 2014, Economía solidaria: local y diversa, México, COLTLAX / CAEA.

Coraggio, José Luis, 2003, Política social y economía del trabajo. Alternativas a la política neoliberal para la ciudad, Buenos Aires, Miño y Dávila / El Colegio Mexiquense.

, 2009, «Economía del trabajo», en Antonio David Cattani, José Luis Coraggio y Jean-Louis Laville, (organizadores), Diccionario de la otra Economía, Buenos Aires, UNGS / Altamira / CLACSO, pp. 133-144.

Dobb, Maurice, 1975, Teoría del valor y la distribución desde Adam Smith, Buenos Aires, Siglo XXI Editores.

Féliz, Mariano, 2011, «El fundamento de la política del vivir bien: la economía política de los trabajadores y las trabajadoras como alternativa», en Ivon Farah y Luciano Vasapollo (coords.), Vivir bien:¿Paradigma no capitalista?, La Paz, Universidad de Roma/CIDES-UMSA/OXFAM, pp. 169-182.

Foster, George M., 1972, Tzintzuntzan, México, FCE.

Fuente, Julio de la, 1977, Educación, antropología y desarrollo de la comunidad, México, INI.

Galafassi, Guido, 2010, «La construcción mancomunada y dialéctica de un nuevo proceso de conocimiento (socio-natural) para una nueva sociedad», en Ivon Farah y Luciano Vasapollo (coords.), Vivir bien:¿Paradigma no capitalista?, La Paz, Universidad de Roma/CIDES-UMSA/OXFAM, pp. 263-278. García-Álvarez, Santiago, 2014, «Sumak kawsay o buen vivir como alternativa al desarrollo en Ecuador. Aplicación y resultados en el gobierno de Rafael Correa (2007-2011)», tesis de doctorado inédita, Madrid, Universidad Complutense.

Geertz, Clifford, 1987, La interpretación de las culturas, Barcelona, Gedisa.

Godelier, Maurice, 1967, Racionalidad e irracionalidad en la economía, México, Siglo XXI Editores.

Godelier, Maurice, 1977, «Modos de producción, relaciones de parentesco y estructuras demográficas», en Maurice Bloch (ed.), Análisis marxistas y antropología social, Barcelona, Anagrama, pp. 13-42. 1989, Lo ideal y lo material, Madrid, Taurus-Alfaguara. 1998, El enigma del don, Barcelona, Paidos.

Goodenough, Ward, 1971, "Cultura, lenguaje y sociedad», en J. S. Kahn (ed.), El concepto de cultura: Textos fundamentales, Barcelona, Anagrama, pp. 157-248.

Gudynas, Eduardo, 2011, «Tensiones, contradicciones y oportunidades de la dimensión ambiental del Buen Vivir», en Ivon Farah y Luciano Vasapollo (coords.), Vivir bien:¿Paradigma no capitalista?, La Paz, Universidad de Roma / CIDES-UMSA/OXFAM, pp. 231-245.

Gudynas, Eduardo y Alberto Acosta, 2011, «El buen vivir o la disolución de la idea del progreso», en Mariano Rojas (coord..), La medición del progreso y del bienestar. Propuestas desde América Latina, México, Foro Consultivo científico y tecnológico, pp. 103-110. 
Guerrero, Javier, 1975, «Moisés Sáenz, el Precursor olvidado», Nueva Antropología, 1(1), pp. 31-55.

Hendel, Verónica, 2011, «De la respuesta a la creación. Re-creando el socialismo, la agricultura y la vida en América Latina», en Ivon Farah y Luciano Vasapollo (coords.), Vivir bien:¿Paradigma no capitalista?, La Paz, Universidad de Roma / CIDES-UMSA/OXFAM, pp. 247-262.

Hinkelammert, Franz, 2009, «Economía para la vida», en Antonio David Cattani, José Luis Coraggio y Jean-Louis Laville (organizadores), Diccionario de la otra economía, Buenos Aires, UNGS / Altamira / CLACSO, pp. 150-157.

Hinkelammert, Franz y Henry Mora Jiménez, 2008, «Reproducción de la vida, utopía y libertad: por una economía orientada hacia la vida», Otra Economía, Revista Latinoamericana de Economía Social y Solidaria, 2(2), pp. 22-27.

Houtart, Francois, 2011, «Los indígenas y los nuevos paradigmas del desarrollo humano», en Ivon Farah y Luciano Vasapollo (coords.), Vivir bien:¿Paradigma no capitalista?, La Paz, Universidad de Roma / CIDES-UMSA/OXFAM, pp. 125-133.

Illich, Ivan, 2006, Obras reunidas, México, FCE.

Kirchhoff, Paul, 1975, «Mesoamérica», en Enciclopedia de México, t. VIII, México.

Le Quang, Matthieu y Tamia Vercoutère, 2013, Ecosocialismo y buen vivir. Diálogo entre dos alternativas al capitalismo, Quito, IAEN.

Lee, Richard, 1981, «La subsistencia de los bosquimanos !Kung: un análisis de input-output», en José Llobera (comp.), Antropología económica. Estudios etnográficos, Barcelona, Anagrama, pp. 35-63.

Lomnitz, Larissa, 1975, Cómo sobreviven los marginados, México, Siglo XXI Editores.

Mamani-Ramírez, Pablo, 2011, "Qamir qamaña: dureza de "estar estando"», en Ivon Farah y Luciano Vasapollo (coords.), Vivir bien:¿Paradigma no capitalista?, La Paz, Universidad de Roma / CIDES-UMSA/OXFAM, pp. 65-76.

Manosalvas, Margarita, 2014, «Buen vivir o sumak kawsay. En busca de nuevos referenciales para la acción pública en Ecuador», Íconos. Revista de Ciencias Sociales, 49, pp. 101-121.

Marx, Karl, 1968a, El Capital, México, FCE.

, 1968b, La ideología alemana, Montevideo, Pueblos Unidos.

,1971, Formaciones económicas precapitalistas, Buenos Aires, Siglo XXI Editores.

Maslow, Abraham, 1998, El hombre autorrealizado: Hacia una psicología del ser, Barcelona, Kairós.

Mauss, Marcel, 1979, «Ensayo sobre los dones. Motivo y forma del cambio en las sociedades primitivas», en Sociología y Antropología, Madrid, Editorial Tecnos.

Medina, Javier,2011, «Acerca delSuma Qamaña», enIvonFarahyLucianoVasapollo(coords.), Vivirbien:¿Paradigmanocapitalista?,LaPaz,UniversidaddeRoma/CIDES-UMSA/OXFAM, pp. 39-64.

Meillassoux, Claude, 1977, Mujeres, graneros y capital, México, Siglo XXI Editores.

Nussbaum, Martha, 2002, Las mujeres y el desarrollo humano, Buenos Aires, Norma.

Oswald, Úrsula, 1991, Estrategias de supervivencia en la Ciudad de México, Cuernavaca, CRIM / UNAM.

Palerm, Juan Vicente, 1997, Los nuevos campesinos, México, UIA. 
Polanyi, Karl, 2006, La gran Transformación, México, FCE. ,2009, El sustento del hombre, Madrid, Capitan Saing Libros.

Ramírez, René, 2010, «La transición ecuatoriana hacia el Buen Vivir», en Irene León (coord.), Sumak Kawsay / Buen vivir y cambios civilizatorios, Quito, FEDAEPS, pp. 125-141.

Razeto, Luis, 1988, Economía de solidaridad y mercado, Santiago de Chile, PET.

Ritzer, George, 2005, La macdonalización de la sociedad. Un análisis de la racionalización en la vida cotidiana, Barcelona, Ariel.

Romero Bedregal, Hugo, 2011, "Vivir bien, hacia un nuevo paradigma de desarrollo no capitalista. Suma qamaña, vivir bien y lg life's good: como procesos civilizatorios», en Ivon Farah y Luciano Vasapollo (coords.), Vivir bien:¿Paradigma no capitalista?, La Paz, Universidad de Roma / CIDES-UMSA/OXFAM, pp. 77-92.

Santos, Boaventura de Sousa, 2012, De las dualidades a las ecologías, La Paz, Red Boliviana de Mujeres Transformando la Economía.

Sejenovich, Héctor, 2011, «La calidad de vida, la cuestión ambiental y sus interrelaciones», en Ivon Farah y Luciano Vasapollo (coords.), Vivir bien:¿Paradigma no capitalista?, La Paz, Universidad de Roma / CIDES-UMSA/OXFAM, pp. 209-232.

Smith, Adam, 2004, La riqueza de las naciones, Longseller.

Smith, Waldemar R., 1981, El sistema de fiestas y el cambio económico, México, FCE.

Toledo, Víctor M. y Narciso Barrera-Bassols, 2008, La memoria biocultural. La importancia ecológica de las sabidurías tradicionales, Barcelona, Icaria.

Tortosa, José María, 2009, «El futuro del maldesarrollo», Revista Obets, 4, pp. 67-83.

Touraine, Alain, 1997, ¿Podremos vivir juntos? iguales y diferentes, México, FCE.

Unceta, Koldo, 2014, "Poscrecimiento, desmercantilización y "buen vivir"», Nueva Sociedad, 252, pp. 136-152.

Vanhulst, Julien y Adrian E. Beling, 2013, «Buen vivir: la irrupción de América Latina en el campo gravitacional del desarrollo sostenible», Revista Iberoamericana de Economía Ecológica, v. 21, pp. 1-14.

Yañez, S, 2006, «El Instituto Nacional de Antropología e Historia: antecedentes, trayectoria y cambios a partir de la creación del Conaculta», Cuicuilco, 13(38), pp. 47-72.

Zaldívar, Víctor Bretón Solo de, 2013, «Etnicidad, desarrollo y "Buen Vivir": Reflexiones críticas en perspectiva histórica», Revista Europea de Estudios Latinoamericanos y del Caribe, 95, pp. 71-95.

Zibechi, Raúl, 2010, «El Buen Vivir como el "otro mundo posible"», Entropía, 9.

Žižek, Slavoj, 2003, El sublime objeto de la ideología, Buenos Aires, Siglo XXI Editores.

Fecha de recepción: 21 de mayo de 2014

Fecha de aceptación: 18 de marzo de 2015 